\title{
Relación entre la micorrización espontánea y la utilización de diferentes abonos orgánicos en el cultivo de algodón (Gossypium hirsutum).
}

Cossoli*, Marcela R.; Rauch, Ruben J.; Correa, Amilcar; Romero, Amalia, M. E.; Iglesias, María C. Cátedra de Microbiología Agrícola. FCA - UNNE. Sargento Cabral 2131 - CP 3400, Corrientes. Tel. /fax:+54(379) 4427589 int. 158

*E-mail: mcossoli@gmail.com.

Introducción: El suelo es un sistema vivo y dinámico, un gran número de microorganismos residen en él y llevan adelanto un amplio rango de funciones. Entre estos se encuentran los hongos formadores de micorrizas arbusculares que forman una simbiosis mutualista con las raíces de la mayoría de las plantas y cuyo efecto más significativo es el mejoramiento de su nutrición, pero este efecto va a depender de la relación costo-beneficio de la simbiosis y el rango de respuesta va a ser afectado por numerosos factores, entre ellos el estado y especie de planta hospedante, la especie del hongo y las condiciones del ambiente rizosférico. El objetivo de este trabajo fue evaluar el comportamiento de la micorrización espontánea en relación a la utilización de abonos orgánicos con diferentes características nutricionales en el cultivo de algodón

Materiales y métodos: Se realizó un ensayo en contenedores utilizando semillas de algodón de la variedad NuOpal (PG $99 \%$ ), utilizando como sustrato un suelo de suelo textura arenosa de baja fertilidad. Se utilizaron cuatro compost generados a partir de diferentes estiércoles: Ave, Bovino, Caprino y Equino; todos se armaron a partir de una relación 1:1 con aserrín. A partir de esta situación todo los composts tenían diferentes características nutricionales. El diseño del ensayo fue en bloques completos al azar con 9 tratamientos y 5 repeticiones. Los tratamientos se generaron a partir de la utilización de los cuatro composts de diferentes orígenes y la utilización de dos dosis: equivalente a 40 tn.ha ${ }^{-1}$ y 20 tn.ha ${ }^{-1}$, además de un tratamiento Testigo. A los 40 días se extrajeron las plantas y las raíces fueron lavadas y teñidas con Azul de tripán, para la observación de la infección micorrícica, pudiendo determinar el \% de micorrización y la observación de las diferentes estructuras fúngicas existentes. Al suelo obtenido de cada tratamiento se le realizó el análisis de contenido de Fósforo. Los datos fueron transformados y se analizaron mediante ANAVA y prueba de Tukey $(p \leq 0,05)$.

Resultados: Al analizar el \% de infección micorrícica, se observó que la situación fue diferente según la dosis de abono utilizada. En el caso de 40 tn.ha ${ }^{-1}$, tanto el compost a partir de estiércol caprino como el testigo fueron mayores significativamente a los tratamientos con compost a partir de estiércol equino y de ave; en cambio cuando se utilizó la dosis de 20 tn.ha ${ }^{-1}$, el tratamiento Testigo y el que tenía compost de estiércol Bovino fueron mayores significativamente a los compost de estiércoles Caprino, Equino y de Ave. Cuando se hizo el análisis de las diferentes estructuras observadas, para todos los tratamientos el \% de arbúsculos fue mayor que el de vesículas, y su distribución entre tratamientos tuvo el mismo comportamiento que el \% de micorrización, tanto para la dosis de 40 tn.ha ${ }^{-1}$ como la de 20 tn.ha ${ }^{-1}$, en cambio en los campos donde solo se observaron hifas no hubo diferencias entre tratamientos en ningún caso. La situación observada pudo relacionarse también al contenido de fósforo de los suelos de los diferentes tratamientos al finalizar el ensayo, ya que los tratamientos con abonos fueron menores o al menos igualaron al testigo en la micorrización (56,7 \%), siendo que este tratamiento fue el que menor fósforo contenía (10,4 ppm). En este sentido, según las dosis utilizadas, el contenido de fósforo fue mayor para todos los tratamientos con la dosis de $40 \mathrm{tn}_{\text {.ha }}{ }^{-1}$ que la de 20 tn.ha ${ }^{-1}$, pero con respecto a las estructuras se pudo observar que en los tratamientos con compost de estiércol de Ave y Caprino, si bien fueron diferentes sus cantidades disminuyeron cuando lo hizo el $\mathrm{P}$, en cambio en los tratamientos con compost de estiércol Bovino y Equino, aumentaron las estructuras cuando este disminuyó.En suelos pobres en nutrientes los valores de micorrización suelen ser altos y cuando la disponibilidad de nutrientes como el $\mathrm{N}$ y el $\mathrm{P}$ aumentan se espera una disminución de la abundancia en la infección micorrícica ya que la planta genera un menor suministro de $\mathrm{C}$.

Conclusiones: Se pudo determinar que en el suelo original existía una considerable proporción de inóculo que se expresó en forma diferenciada en relación al contenido de $\mathrm{P}$ proporcionado con el agregado de abonos de diferentes características. 